\title{
Differences in Frequency of Transposable Elements Presence in Botrytis cinerea Populations from Several Hosts in Greece
}

Stylianos Samuel, Thomas Veloukas, Antonios Papavasileiou, and George S. Karaoglanidis, Aristotelian University of Thessaloniki, Faculty of Agriculture, Plant Pathology Laboratory, POB 269, 54124, Thessaloniki, Greece

\begin{abstract}
Samuel, S., Veloukas, T., Papavasileiou, A., and Karaoglanidis, G. S. 2012. Differences in frequency of transposable elements presence in Botrytis cinerea populations from several hosts in Greece. Plant Dis. 96:1286-1290.

This study was conducted primarily to investigate the presence and frequency distribution of the transposable elements Boty and Flipper in populations of the necrotroph plant pathogen Botrytis cinerea in Greece. In total, 334 isolates were collected from diseased grape, strawberry, tomato, cucumber, kiwifruit, and apple fruit during 2009. The presence of the two transposable elements was based on polymerase chain reaction detection. Results showed that all the sampled hosts occurred in sympatry, with four possible different genotypes (transposa type carrying both transposable elements, Boty type carrying only the Boty element, Flipper type carrying only the Flipper element, and vacuma type carrying neither transposable element). Marked differences in genotype frequencies among populations were observed. In tomato, cucumber, grape, and strawberry, transposa isolates carrying both elements were predominant in the populations whereas, in kiwifruit and apple fruit populations, the vacuma isolates were prevailing. Furthermore, in kiwi and apple fruit populations, high frequencies

of Flipper-type isolates were observed. In an attempt to explain the observed predominance of vacuma isolates in kiwifruit populations, the mycelial growth rate of a set of vacuma isolates was compared with the mycelial growth rate of a set of transposa isolates at three different temperatures $\left(0,10\right.$, and $\left.20^{\circ} \mathrm{C}\right)$. The same set of isolates was used to compare pathogenicity of isolates on wound-inoculated kiwifruit incubated at two different temperatures $\left(0\right.$ and $\left.20^{\circ} \mathrm{C}\right)$, in terms of disease incidence and disease severity. In addition, the selected isolates were used to compare their ability in causing latent infections on kiwifruit in the field. The results showed that vacuma and transposa isolates had similar mycelial growth rates at the limiting temperatures of 0 and $10^{\circ} \mathrm{C}$, while vacuma isolates grew faster at the optimum temperature of $20^{\circ} \mathrm{C}$. Similarly, there was no significant difference regarding pathogenicity on kiwifruit between transposa and vacuma isolates. However, artificial inoculations conducted on blossoms in the field showed that vacuma isolates caused significantly higher incidence of latent infections.
\end{abstract}

Botrytis cinerea Pers., the anamorph of the ascomycete fungus Botryotinia fuckeliana (de Bary) Whetzel, is a cosmopolitan fungus attacking more than 200 plant species in the temperate zone worldwide. It is a necrotrophic plant pathogen causing a disease known commonly as gray mold. All plant organs, including flowers, leaves, shoots, and soil storage organs, are susceptible to Botrytis spp. attacks. However, the most important damages are caused on fruit due to pre- or post-harvest decay (6).

Several genetic studies have shown that Botrytis cinerea is a highly heterogeneous fungal species $(18,24)$. The main sources of this high genetic variability have been reviewed by Beever and Weeds (3) and include (i) the heterocaryosis and parasexual cycle observed very often in the pathogen, (ii) sexual reproduction, and (iii) extrachromosomal elements such as mycoviruses and the presence of transposable elements.

Until the end of 1990s decade, B. cinerea was considered to be a single generalist species. However, identification of two transposable elements, Boty and Flipper, within the fungal genome $(5,17)$ led to a grouping based on the presence or absence of these transposable elements. Fungal strains carrying both or at least one of the two transposable elements were grouped as B. cinerea var. transposa, while fungal strains without either transposable element were grouped as B. cinerea var. vacuma (13). Later on, the fungus was clustered in two different groups, group I and group II, based on DNA polymorphism revealed by microsatellite markers and the level of sensitivity to the hydroxyanilide fungicide fenexamid $(1,10)$. Strains that were of vacuma type and simultaneously natu-

Corresponding author: G. Karaoglanidis, E-mail: gkarao@agro.auth.gr

Accepted for publication 9 April 2012.

http://dx.doi.org/10.1094/PDIS-01-12-0103-RE

(C) 2012 The American Phytopathological Society rally resistant to fenhexamid belonged in group I whereas vacuma strains that were fenhexamid-sensitive along with the transposa type strains belonged in group II $(8,9)$. Although these strains can be found in sympatry on several hosts, the genetic variability described in the above-mentioned reports suggest that $B$. cinerea is a complex of cryptic species. Moreover, several recent studies have shown that isolates belonging to different groups may vary in host range, temporal succession, or in phenotypic characteristics $(13,19,20,23,24)$. Recently, $B$. cinerea group I was established as a new fungal species called $B$. pseudocinerea based on phylogenetic, biological, morphological, and ecological criteria (27).

Despite the economic impact of gray mold on several crops, there are no detailed data of $B$. cinerea populations in Greece. Such information can help toward the development of more effective strategies to control and manage the disease. The current study was conducted to investigate the frequency of $B$. cinerea types in isolates obtained from the most important hosts of the pathogen in Greece, based on the detection of transposable elements. During the course of the study, significant differences in $B$. cinerea type frequencies were observed among the hosts sampled. To explore parameters implicated in these differences, three additional sets of experiments were designed to investigate the effect of temperatures on mycelial growth, on the pathogenicity after wound inoculation of kiwifruit, and the ability of transposa and vacuma isolates of $B$. cinerea to cause latent infections on kiwifruit.

\section{Materials and Methods}

Sample collection. Isolates of B. cinerea were collected from diseased strawberry, grape, apple, kiwifruit, tomato, and cucumber fruit originating from the region of Central Macedonia, northern Greece, the main agricultural region of the country during 2009. In strawberry, tomato, cucumber, and grape fields, the sampling was carried out during the period of harvest, whereas samples from apple and kiwifruit were taken from fruit with gray mold developed in cold storage. For each host, five to six different fields or 
greenhouses were sampled. From all the hosts, only diseased fruit were sampled and, from each fruit, only one isolate was obtained. In total, 82, 55, 59, 50, 47, and 41 isolates were obtained from strawberry, grape, kiwifruit, apple, cucumber, and tomato, respectively. Single-spore isolates were maintained on potato dextrose agar (PDA) slants at $4^{\circ} \mathrm{C}$ until use.

DNA isolation. To extract DNA, all the isolates included in the study were grown in potato dextrose broth (Sigma-Aldrich) for 3 days at $25^{\circ} \mathrm{C}$. Then, the mycelium was harvested by filtration, dried, lyophilized, ground to a fine powder using micropestles (Eppendorf International), and stored at $-20^{\circ} \mathrm{C}$ until use. DNA was extracted using the Qia Puregene Core Kit A (Qiagen GmbH) according to the manufacturer's protocol. The concentration of the extracted DNA was measured using a UV spectrophotometer (Gene Quant2; Pharmacia Biotech).

Detection of transposable elements Boty and Flipper. To detect the presence of either or both Boty and Flipper transposable elements, the polymerase chain reaction (PCR) approach developed by Ma and Michailides (18) was used. Primer pair F300 (5'GCA CAA AAC CTA CAG AAG A-3') and F1550 (5'-ATT CGT TTC TTG GAC TGT A-3') was used to detect the Flipper element while, for the detection of the Boty element, the primer pair BotyF4 (5'-CAG CTG CAG TAT ACT GGG GGA-3') and BotyR4 (5'-GGT GCT CAA AGT GTT ACG GGA G-3') was used. PCR reaction reagents and the amplification protocol were as described by Ma and Michailides (18). PCR reaction mixtures were incubated in a PTC 200 thermal cycler (MJ Research) and the PCR products were size verified in $1.5 \%$ agarose gels in Tris-borateEDTA buffer, supplemented with ethidium bromide $\left(0.1 \mu \mathrm{g} \mathrm{ml}^{-1}\right)$ by electrophoresis, and viewed under UV light.

Distinction between group I and group II isolates. All the vacuma isolates detected at the previous step were further tested to identify whether they belong to $B$. cinerea group I or group II. The $B$. cinerea incompatibility locus (Bc-hch) was used as molecular marker. The distinction was based on a PCR-restriction fragment length polymorphism (RFLP) method developed by Fournier et al. (11). Two group I isolates kindly provided by Prof. M. Hahn (Technical University of Kaiserslautern, Germany) were included in the study as positive controls.

Mycelial growth rate assays at different temperatures. The hyphal growth rate of 12 transposa type (carrying both the Boty and Flipper elements) isolates and 12 vacuma type isolates, randomly selected from the kiwifruit subpopulation, was measured at three different temperatures $\left(0,10\right.$, and $\left.20^{\circ} \mathrm{C}\right)$ on PDA. Mycelial plugs $(5 \mathrm{~mm}$ in diameter) from 3 -day-old cultures were transferred to the center of $9-\mathrm{cm}$ petri dishes. The cultures (three replicate cultures per isolate and temperature) were incubated in the dark. Two perpendicular colony diameters were measured on the bottom of each plate at 24-h intervals until the colony had reached the edge of the petri dish. Agar plug diameters were subtracted from every measurement. The average daily hyphal growth rate per isolate was calculated per temperature. The experiment was repeated twice.

Incidence of latent infections. The same 24 isolates used for mycelial growth rate measurements were also used in experiments to determine the ability of transposa and vacuma isolates in causing latent infection on kiwifruit and the pathogenicity assays on detached kiwifruit. To test the ability of transposa and vacuma isolates in causing latent infections, kiwifruit blossoms ('Hayward') were artificially inoculated at the stage of full bloom. Inoculum was prepared with spores obtained from 12-day-old colonies grown on PDA. Spore suspension in distilled water were adjusted to a concentration of $2 \times 10^{5}$ spores $\mathrm{ml}^{-1}$ with the use of a hemocytometer. For each isolate, five replicate flower-bearing shoots were sprayed with the conidial suspension until run-off. Artificial inoculation was conducted before sunset and the inoculated shoots were covered with plastic bags to maintain high relative humidity. The bags were removed the following morning. Ten replicate shoots were sprayed with sterile water and served as the control treatment used to estimate naturally occurring infections of fruit.
To estimate the frequency of latent infections on the fruit developed on the artificially inoculated shoots, the BOTMON method was used (21). From each replicate shoot, 10 fruit were collected in late September, approximately 1 month before commercial harvest of kiwifruit in Greece. The fruit were transferred into the laboratory and the receptacles were removed and surface-sterilized by immersing them in sodium hypo-chlorite solution $5 \%$ (vol/vol) for $1 \mathrm{~min}$. Then, the receptacles were plated in acidified PDA and incubated at $7^{\circ} \mathrm{C}$ for 6 days and for an additional 3 days at $23^{\circ} \mathrm{C}$. After the end of the incubation period, the number of receptacles showing $B$. cinerea colonies was counted and the percentage of infected receptacles was estimated per isolate.

Artificial inoculations on detached-wounded kiwifruit. Hayward kiwifruit were harvested from a commercial orchard located in the region of Veria, northern Greece. Fruit were harvested when they reached tissue firmness of $60.5 \pm 2.3 \mathrm{~N}$ and soluble solids content of $7.9 \pm 0.1 \%$ and were selected on the basis of shape and size uniformity (fruit without defects and mean weight $95 \pm 5 \mathrm{~g}$ ). The fruit were disinfected by immersion in 5\% sodium hypochlorite solution ( $\mathrm{vol} / \mathrm{vol}$ ) for $1 \mathrm{~min}$. After removing them from the disinfectant solution, they were rinsed three times in sterile, deionized water and subsequently air dried. After drying, fruit were inoculated artificially with $100 \mu \mathrm{l}$ of conidia suspension $\left(2 \times 10^{5}\right.$ spores $\mathrm{ml}^{-1}$ ) of the 24 isolates used in the mycelia growth and latent infections experiments. Inoculum was prepared as described previously. It has been found that the preferred infection site of $B$. cinerea in kiwifruit is the stem scar wound, which is created at the point of harvest when the fruit is snapped from its pedicel (25). Consequently, artificial inoculations of the fruit were conducted through the wound which was made from the removal of the stemend of the fruit with a sterilized scalpel. Fruit treated with sterile water were used as control. Then, fruit were placed on wire-mesh platforms (20 fruits per box) in plastic boxes ( 23 by 31 by $10 \mathrm{~cm}$ [length by width by height]). Water $(20 \mathrm{ml})$ was added to each box and the boxes were then covered to maintain high relative humidity. Following inoculation, the fruit were incubated at two temperatures $\left(0\right.$ and $20^{\circ} \mathrm{C}$, two replicates of 20 fruits per isolate and incubation temperature). Fruit placed at $20^{\circ} \mathrm{C}$ were incubated for 13 days while fruit placed at $0^{\circ} \mathrm{C}$ were incubated for 60 days. At the end of the incubation periods, the number of fruit with disease symptoms was recorded and the percentage of infected kiwifruit was determined. Disease severity was also assessed by measuring the depth (in millimeters) of decay. The experiment was repeated two times.

Data analysis. Frequency distributions of isolate types revealed in each host sampled were compared using the $\chi^{2}$ test. For data analysis of mycelial growth rate, disease incidence, disease severity, and measurements of receptacle colonization, the isolates were grouped according to their genotype. Mean values of each group were compared by the pairwise Student's $t$ test. Percentage values were transformed to arcsine $\sqrt{ } \%$ for statistical analysis. All the statistical analysis tests were supported by the software package SPSS v17.0 (SPSS Inc.).

\section{Results}

Frequency of transposable elements and distinction between group I and group II isolates. PCR-based detection of the two transposable elements showed that, in all the sampled hosts, all four possible Botrytis types (Boty and Flipper type, Boty type, Flipper type, and Vacuma type) existed. However, there were differences in the frequency of these types within each sampled host population (Fig. 1). In strawberry, tomato, cucumber, and grape, the most prevalent genotype was that carrying both transposable elements Boty and Flipper (transposa type) at frequencies ranging from $50 \%$ of the isolates in the strawberry population to $77 \%$ in the tomato population. In contrast, transposa isolates were of low frequency, $17 \%$ in the kiwifruit and $10 \%$ in the apple population. Isolates carrying neither transposable element (vacuma type) were found at frequencies of 12 to $24 \%$ in the tomato, cucumber, strawberry, and grape population, whereas this 
type was the most prevalent in kiwifruit (46\%) and apple (55\%) population. Isolates carrying only the Flipper element were observed in all the sampled hosts but frequencies of this type were relatively high in the kiwifruit and apple populations, with values of 30 and $24 \%$, respectively. Similarly, isolates carrying only the Boty element were detected in all the sampled hosts but the frequency of detection showed a similar pattern among hosts, with values of 2 to $14 \%$ of the populations. The PCR-RFLP method applied to distinguish group I and group II strains based on the polymorphism of Bc-hch locus showed that none of the vacuma isolates from any host belonged to group I.

The $\chi^{2}$ analysis of the isolate-type frequencies showed that the grape population had a similar $(P>0.05)$ distribution to that of tomato, cucumber, and strawberry whereas it was significantly different from that of kiwifruit and apple (Table 1). The population of tomato showed a similar $(P>0.05)$ distribution to that of cucumber, and strawberry but it was different $(P<0.05)$ from that of kiwifruit and apple (Table 1). In addition, the distributions of the cucumber and strawberry populations were different $(P<0.05)$ from that of kiwifruit and apple, whereas there was no difference $(P>0.05)$ in the type frequencies between the apple and kiwifruit populations (Table 1).

Mycelial growth rates of transposa and vacuma isolates. As expected, mycelial growth rates of the isolates tested was significantly affected by the temperature tested. For both isolate types, the higher growth rates were observed at $20^{\circ} \mathrm{C}$, with mean values of $22.3 \mathrm{~mm} /$ day for the transposa isolates and $23.4 \mathrm{~mm} /$ day for the vacuma isolates, which were significantly different $(P<0.05$; Fig. 2 ). The isolates were able to grow even at $0^{\circ} \mathrm{C}$, although this temperature, along with $10^{\circ} \mathrm{C}$, was limiting for mycelial growth. In both temperatures, the mean mycelial growth of transposa isolates, as a group, did not differ significantly $(P>0.05)$ from the mean mycelial growth of the vacuma isolates as a group, showing respective values of 14.4 and $14.9 \mathrm{~mm} /$ day at $10^{\circ} \mathrm{C}$; while, at $0^{\circ} \mathrm{C}$, the mycelial growth rates were 2.8 and $3.1 \mathrm{~mm} /$ day, respectively (Fig. 2).

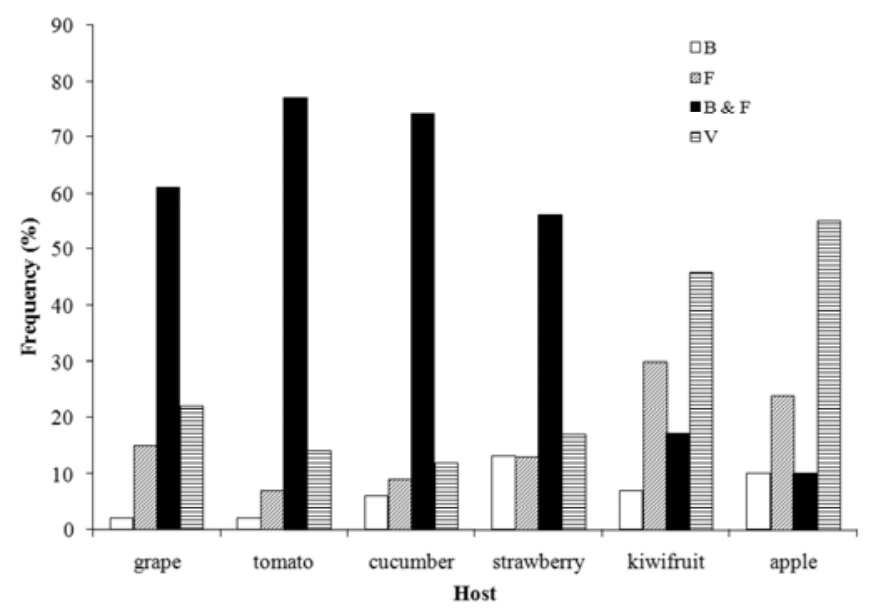

Fig. 1. Frequency distribution of Botrytis cinerea types $(B=B$ Boty, $F=$ Flipper, $B$ \& $F$ $=$ both, and $\mathrm{V}=$ vacuma) in fungal populations collected from several hosts in Greece.
Incidence of latent infections. Artificial inoculations of kiwifruit at full bloom stage led to a moderate to high colonization of the fruit receptacles, as shown by the measurements conducted on PDA. Natural infections in shoots sprayed with water, serving as control, were at very low levels, with a mean frequency of $1 \%$. Although a certain degree of variability existed among the tested isolates, mean receptacle colonization in fruit obtained from shoots inoculated with vacuma isolates was significantly higher $(P>0.05)$ than that observed in fruit inoculated with transposa isolates, with values of 53.7 and $18.2 \%$, respectively (Table 2).

Pathogenicity of transposa and vacuma isolates on detachedkiwifruit. All the isolates used in the study were pathogenic to kiwifruit despite the fact that variability existed among isolates, both in terms of disease incidence that they caused on kiwifruit and disease severity (decay depth) on rotted fruit. Disease incidence was much lower when fruit were incubated at $0^{\circ} \mathrm{C}$ compared with the disease incidence on the fruit incubated at $20^{\circ} \mathrm{C}$ (Table 2). At $0^{\circ} \mathrm{C}, 45 \%$ of fruit inoculated by the transposa isolates showed disease symptoms while $46 \%$ of the fruit inoculated by the vacuma isolates were diseased $(P>0.05)$. Similarly, when fruit were incubated at $20^{\circ} \mathrm{C}$, there was no significant difference $(P>0.05)$ in disease incidence caused by transposa and vacuma isolates, with 82 and $76 \%$ infected fruit, respectively (Table 2). Furthermore, there was no difference $(P>0.05)$ in the disease severity caused by the transposa and vacuma isolates considered as groups of isolates when inoculated fruit were incubated at $0^{\circ} \mathrm{C}$, while disease severity was higher $(P<0.05)$ on fruit inoculated by the transposa isolates incubated at $20^{\circ} \mathrm{C}$ compared with the disease severity caused by the vacuma isolates at the same temperature (Table 2).

\section{Discussion}

None of the $B$. cinerea isolates tested in the current study belonged in group I (B. pseudocinerea) as revealed by PCR-RFLP of the $\mathrm{Bc}-h c h$ locus. This criterion, along with natural resistance to the sterol biosynthesis inhibitor fenhexamid, constituted the two main criteria for grouping B. cinerea isolates in group I (9). The presence of group I isolates has been reported in a considerable number of reports at low frequency levels of 2.5 to $15 \%$ of the population $(16,18,20)$, whereas four recent studies with $B$. cinerea isolates from grape and other hosts revealed a complete absence of group I strains $(7,14,15,26)$. The absence or the low frequency of group I strains observed in the previous reports suggest that it is of minor epidemiological importance. Moreover, group I isolates may be of low agricultural importance, too, because a previous study using multiple gene genealogies showed an absence of genetic exchange between group I and group II strains, suggesting that they belong in distinct phylogenetic species (9). In our study all the pathogen samples originated from diseased fruit, while it is known that group I isolates are usually observed on attacked leaves and blossoms. Whether the observed absence of group I isolates was due to the sampling strategy or to a real absence of these isolates in Greece remains to be further investigated.

In our study, the grape, tomato, cucumber, and strawberry populations of $B$. cinerea showed similar frequency patterns based on transposable elements. Samples from tomato, cucumber, and strawberry were obtained from greenhouse-grown plants, while samples from grape were obtained from open-field-grown plants.

Table 1. Comparison of frequency distributions of transposable element types (Boty, Flipper, transposa, and vacuma type) in Botrytis cinerea populations collected from several hosts in Greece, based on a $\chi^{2}$ analysis $^{z}$

\begin{tabular}{|c|c|c|c|c|c|c|c|c|c|c|}
\hline \multirow[b]{2}{*}{ Host } & \multicolumn{2}{|c|}{ Tomato } & \multicolumn{2}{|c|}{ Cucumber } & \multicolumn{2}{|c|}{ Strawberry } & \multicolumn{2}{|c|}{ Kiwifruit } & \multicolumn{2}{|c|}{ Apple } \\
\hline & $\chi^{2}$ value & $P$ value & $\chi^{2}$ value & $P$ value & $\chi^{2}$ value & $P$ value & $\chi^{2}$ value & $P$ value & $\chi^{2}$ value & $P$ value \\
\hline Grape & 3.2 & 0.39 & 2.9 & 0.40 & 4.7 & 0.19 & 21.0 & $0.000 *$ & 19.7 & $0.000^{*}$ \\
\hline Tomato & $\ldots$ & $\ldots$ & 1.2 & 0.73 & 9.6 & 0.07 & 39.0 & $0.000 *$ & 34.1 & $0.000^{*}$ \\
\hline Cucumber & $\ldots$ & $\ldots$ & $\ldots$ & $\ldots$ & 4.6 & 0.20 & 29.2 & $0.000 *$ & 26.0 & $0.000^{*}$ \\
\hline Strawberry & $\ldots$ & $\ldots$ & $\ldots$ & $\ldots$ & $\ldots$ & $\ldots$ & 16.1 & $0.001 *$ & 14.3 & $0.003^{*}$ \\
\hline Kiwifruit & $\ldots$ & $\ldots$ & $\ldots$ & $\ldots$ & $\ldots$ & $\ldots$ & $\ldots$ & $\ldots$ & 1.22 & 0.74 \\
\hline
\end{tabular}

${ }^{\mathrm{z} P}$ values lower than 0.05 indicate statistically significant $\chi^{2}$ values. 
Such a similarity may be explained by a constant gene flow from greenhouses to open field areas and vice versa through conidia migration, as has been suggested in previous reports $(2,4)$. Despite the fact that greenhouses may act as a bottleneck process leading to genetic drift if entrance of external inoculum is limited (15), this is far from the commonly used agronomic practices in Greece that include (i) rotation of Solanaceae crops, such as tomato, eggplant, and pepper, with Curcubitaceae crops such as cucumber and squash; (ii) opening of roof and side greenhouse windows during the warm hours of the day for ventilation; and (iii) removal of diseased parts from the plants and abandonment of them at edges of the fields or the greenhouses. Such factors, associated with the absence of a strict host-specificity of the pathogen, may explain the observed similarity in the pathogen types in these crops. However, further research is required to elucidate the presence or absence of true genetic similarity among the populations showing similar frequencies of transposable element-based types of the pathogen.

One of the most important findings of the current report was that the vacuma isolates were predominant in the kiwifruit and apple fruit population whereas, as expected, the transposa type isolates were predominant in the remaining sampled hosts. Although it is well established that vacuma isolates fluctuate seasonally on grape, being predominant early in the season and decreasing in frequency after veraison $(12,13,20)$, predominance of vacuma strains within the fungal population at the end of the vegetative period has been reported only on green pea (12). The observed differences in $B$. cinerea type frequency distribution between kiwifruit or apple fruit and other hosts cannot be explained by differences in geographic distribution because the sampled fields for all the hosts were in the same geographical region characterized by the absence of natural borders. A similar difference in B. cinerea type frequency distribution between kiwifruit and other hosts such as grape or tomato has also been observed in the Chilean population of the pathogen (24), although only 14 kiwifruit isolates were used. Furthermore, the

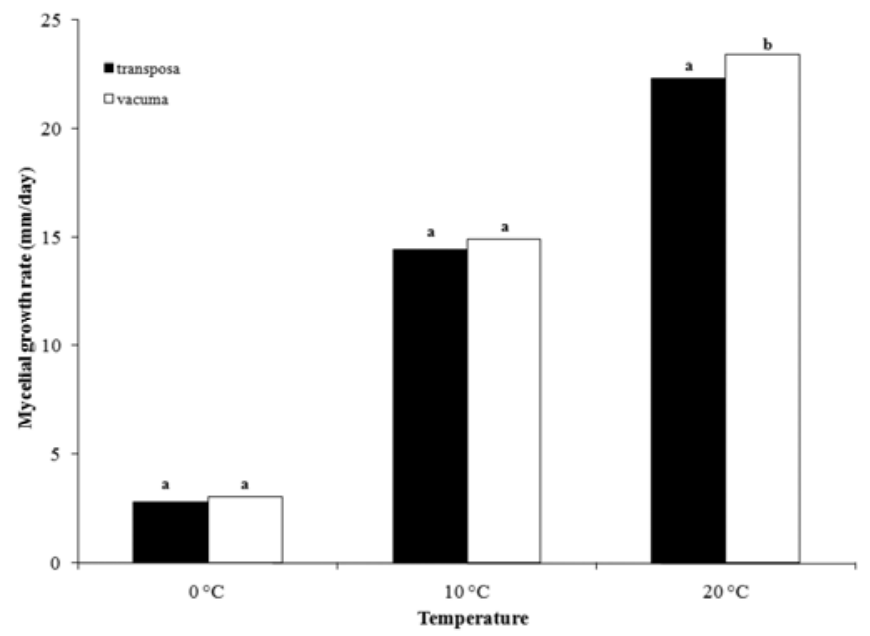

Fig. 2. Mycelial growth rate (millimeters per day) of transposa and vacuma Botrytis cinerea isolates at three different temperatures. Different letters in columns indicate significant differences according to Student's $t$ test at $P=0.05$. frequency of isolates carrying only the Flipper element both in the kiwifruit and apple populations was surprisingly high. In several previous reports, such isolates were either totally absent $(16,18,24)$ or present at very low frequencies (1). Detection of $B$. cinerea isolates carrying only the Flipper element at high frequencies has been reported only in two previous studies from strawberry and grape $(22,26)$. Whether these Flipper-type isolates originated by crosses between vacuma and transposa isolates or they constitute a distinct $B$. cinerea type requires further research.

The observed higher frequency of the vacuma type isolates in the kiwifruit and apple populations raised the question of why there was such a difference between the sampled hosts. Based on the fact that both apple and kiwifruit populations had been collected from decayed fruit cold-stored in packinghouses, we hypothesized that vacuma isolates can either grow faster than transposa under the storage temperature $\left(0^{\circ} \mathrm{C}\right)$ or, if this is not the case, they were more aggressive on hosts such as kiwifruit or apple. To test these hypotheses, we carried out three additional set of experiments comparing the mycelial growth rate on artificial nutrient media, the pathogenicity on wound-inoculated kiwifruit, and the ability to cause latent infections in the field. Comparisons of mycelial growth rate at three different temperatures showed that temperature affects both transposa and vacuma isolates similarly. For both types, the higher growth rate was observed at the temperature of $20^{\circ} \mathrm{C}$ although, in comparison, vacuma isolates showed higher mycelial growth than the transposa isolates at this temperature. This is in agreement with the finding of Martinez et al. (20), who similarly found that, at $20^{\circ} \mathrm{C}$, the vacuma isolates grew faster. However, there was no difference in the mycelial growth rates between vacuma and transposa isolates at 0 and $10^{\circ} \mathrm{C}$. The absence of difference in mycelial growth rates primarily at $0^{\circ} \mathrm{C}$ is of particular importance because this is the temperature of storage for kiwifruit and apple fruit. Therefore, the growth rate at $0^{\circ} \mathrm{C}$ cannot account for the prevailing occurrence of the vacuma isolates within the population collected from cold-stored fruit such as kiwifruit.

The results of the pathogenicity tests showed that disease incidence caused by transposa and vacuma isolates after wound inoculation of the kiwifruit was similar at both tested temperatures. The selected method of fruit inoculation did not discriminate the two distinct pathogen types according to their pathogenicity. However, it is well established that $B$. cinerea can also penetrate kiwifruit tissues after colonizing senescent sepals, petals, or anthers and remain latent in the tissues until the ripening of the fruit, most often during storage. This method of fruit infection represents one of the three possible infection methods (21). To investigate the hypothesis that vacuma and transposa isolates differed in their ability to cause latent infections in kiwifruit, an artificial inoculation experiment in the field was designed. Measurements of receptacle colonization by the pathogen in fruit obtained from shoots inoculated at the full bloom stage showed that a significantly higher pathogen incidence was observed in fruit inoculated with the vacuma isolates. Such results suggest that latent infections early in the season are caused predominantly by the vacuma isolates, while wound-mediated infections occurring during harvest at the stem end of the kiwifruit may be caused with equal probability by both transposa and vacuma isolates. Consequently, the higher frequency of vacuma isolates observed in cold-stored fruit could be

Table 2. Pathogenicity of Botrytis cinerea vacuma and transposa isolates on detached kiwifruit incubated at 0 and $20^{\circ} \mathrm{C}$ and isolate ability in causing latent infections on kiwifruit

\begin{tabular}{|c|c|c|c|c|c|}
\hline \multirow[b]{3}{*}{ Isolate type } & \multicolumn{4}{|c|}{ Pathogenicity on detached kiwifruit ${ }^{y}$} & \multirow[b]{3}{*}{ Colonized receptacles $(\%)^{z}$} \\
\hline & \multicolumn{2}{|c|}{$\mathbf{0}^{\circ} \mathbf{C}$} & \multicolumn{2}{|c|}{$20^{\circ} \mathrm{C}$} & \\
\hline & Infected fruit (\%) & Decay length $(\mathbf{m m})$ & Infected fruit (\%) & Decay length (mm) & \\
\hline Transposa & $45.3 \mathrm{a}$ & $14.2 \mathrm{a}$ & $82.5 \mathrm{a}$ & $8.9 \mathrm{a}$ & $18.2 \mathrm{~b}$ \\
\hline Vacuma & $46.7 \mathrm{a}$ & $11.9 \mathrm{a}$ & $76.7 \mathrm{a}$ & $6.8 \mathrm{~b}$ & $53.7 \mathrm{a}$ \\
\hline
\end{tabular}

${ }^{y}$ Measurements of fruit infection (\%) and decay length were measured after 60 and 13 days for fruit incubated at 0 and $20^{\circ} \mathrm{C}$, respectively. Different letters in the columns indicate significant differences according to Student's $t$ test at $P=0.05$.

${ }^{\mathrm{z}}$ Colonized receptacles $(\%)$ were measured on kiwifruit obtained from shoots artificially inoculated with the pathogen at the full bloom stage. 
explained by their higher ability to cause latent infections. A similar explanation could be valid also for apple fruit in which $\mathrm{B}$. $\mathrm{Ci}$ nerea behaves also as a latent pathogen; however, experimental confirmation is required.

In conclusion, the results of the current report strongly support previous findings that the pathogen's host shapes its genetic structure, despite the absence of a strict host specificity (8). Knowledge of population genetic structure on the attacked hosts is fundamental for developing rational control strategies. However, further research is required for a deeper understanding of the genetic structure of this important pathogen using more powerful molecular markers such as microsatellites.

\section{Acknowledgments}

We thank G. Menexes for his aid in the statistical analysis of the results, M. Hahn for providing the group I isolates used in the study, and T. Kapari-Isaia and L. Papayiannis (Agricultural Research Institute of Cyprus, Nicosia, Cyprus) for providing unlimited support to S. Samuel.

\section{Literature Cited}

1. Albertini, C., Thébaud, G., Fournier, E., and Leroux, P. 2002. Eburicol 14ademethylase gene (cyp51) polymorphism and speciation in Botrytis cinerea. Mycol. Res. 106:1171-1178.

2. Alfonso, C., Raposo, R., and Melgarejo, P. 2000. Genetic diversity in Botrytis cinerea populations on vegetable crops in greenhouses in south-eastern Spain. Plant Pathol. 49:243-251.

3. Beever, R. E., and Weeds, P. L. 2004. Taxonomy and genetic variation of Botrytis and Botryotinia. Pages 29-52 in: Botrytis: Biology, Pathology and Control. Y. Elad, B. Williamson, P. Tudzynski, and N. Delen, eds. Springer, Dordrecht, The Netherlands.

4. Decognet, V., Bardin, M., Trottin-Caudal, Y., and Nicot, P. C., 2009. Rapid change in the genetic diversity of Botrytis cinerea populations after the introduction of strains in a tomato glasshouse. Phytopathology 99:185-193.

5. Diolez, A., Marches, F., Fortini, D., and Brygoo, Y. 1995. Boty, a longterminal-repeat retroelement in the phytopathogenic fungus Botrytis cinerea. Appl. Environ. Microbiol. 61:103-108.

6. Elad, Y., Williamson, B., Tudzynski, P., and Delen, N., 2004. Botrytis spp. and diseases they cause in agricultural ecosystems - an introduction. Pages 1-8 in: Botrytis: Biology, Pathology and Control. Y. Elad, B. Williamson, P. Tudzynski, and N. Delen, eds. Springer, Dordrecht, The Netherlands.

7. Esterio, M., Muñoz, G., Ramos, C., Cofré, G., Estévez, R., Salinas, A., and Auger, J. 2011. Characterization of Botrytis cinerea isolates present in Thompson seedless table grapes in the Central Valley of Chile. Plant Dis. 95:683-690.

8. Fournier, E., and Giraud, T. 2008. Sympatric genetic differentiation of a generalist pathogenic fungus, Botrytis cinerea, on two different host plants, grapevine and bramble. J. Evol. Biol. 21:122-132.

9. Fournier, E., Giraud, T., and Brygoo, Y., 2005. Partition of the Botrytis cinerea complex in France using multiple gene genealogies. Mycologia 97:1251-1267.

10. Fournier, E., Giraud, T., Loiseau, A., Vautrin, D., Estoup, A., Solignac, M., Cornuet, J. M., and Brygoo, Y. 2002. Characterization of nine polymorphic microsatellite loci in the fungus Botrytis cinerea (Ascomycota). Mol. Ecol.
Notes 2:253-255.

11. Fournier, E., Levis, C., Fortini, D., Leroux, P., Giraud, T., and Brygoo, Y. 2003. Characterization of $\mathrm{Bc}-h c h$, the Botrytis cinerea homolog of the Neurospora crassa het-c vegetative incompatibility locus, and its use as a population marker. Mycologia 95:251-261.

12. Giraud, T., Fortini, D., Levis, C., Lamarque, C., Leroux, P., LoBuglio, K., and Brygoo, Y. 1999. Two sibling species of the Botrytis cinerea complex, transposa and vacuma are found in sympatry on numerous host plants. Phytopathology 89:967-973.

13. Giraud, T., Fortini, D., Levis, C., Leroux, P., and Brygoo, Y. 1997. RFLP markers show genetic recombination in Botryotinia fuckeliana (Botrytis cinerea) and transposable elements reveal two sympatric species. Mol. Biol. Evol. 14:1177-1185.

14. Isenegger, D. A., Ades, P. K., Ford, R., and Taylor, P. W. J. 2008. Status of the Botrytis cinerea complex and microsatellite analysis of transposon types in South Asia and Australia. Fungal Divers. 29:17-27.

15. Karchani-Balma, S., Gautier, A., Raies, A., and Fournier, E., 2008. Geography, plants, and growing systems shape the genetic structure of Tunisian Botrytis cinerea populations. Phytopathology 98:1271-1279.

16. Kretchmer, M., and Hahn, M. 2008. Fungicide resistance and genetic diversity of Botrytis cinerea isolates from a vineyard in Germany. J. Plant Dis. Prot. 115:214-219.

17. Levis, C., Fortini, D., and Brygoo, Y. 1997. Flipper, a mobile Fot1-like transposable element in Botrytis cinerea. Mol. Gen. Genet. 254:674-680.

18. Ma, Z., and Michailides, T. J. 2005. Genetic structure of Botrytis cinerea populations from different host plants in California. Plant Dis. 89:10831089.

19. Martinez, F., Blancard, D., Lecomte, P., and Levis, C. 2003. Phenotypic differences between vacuma and transposa subpopulations of Botrytis cinerea. Eur. J. Plant Pathol. 109:479-488.

20. Martinez, F., Dubos, B., and Fermaud, M. 2005. The role of saprotrophy and virulence in the population dynamics of Botrytis cinerea in vineyards. Phytopathology 95:692-700.

21. Michailides, T. J., and Elmer, P. A. G. 2000. Botrytis gray mold of kiwifruit caused by Botrytis cinerea in the United States and New Zealand. Plant Dis. 84:208-223.

22. Milicevic, T., Topolovec-Pintaric, S., Cvjetkovic, B., Ivic, D., and Duralija, B. 2006. Sympatric populations of Botrytis cinerea on strawberries based on the content of transposable elements and their connection with resistance to botryticides. Acta Hortic. 708:115-118.

23. Mirzaei, S., Goltapeh, E. M., Shans-Bakhsh, M., Safaie, N., and Chaichi, M. 2009. Genetic and phenotypic diversity among Botrytis cinerea isolates in Iran. J. Phytopathol. 157:474-482.

24. Munoz, G., Hinrichsen, P., Brygoo, Y., and Giraud, T. 2002. Genetic characterization of Botrytis cinerea populations in Chile. Mycol. Res. 106:594601.

25. Sharrock, K., and Hallett, I. C. 1991. Physiology of Botrytis infection in kiwifruit. Acta Hortic. 297:551-557.

26. Váczy, K. Z., Sándor, E., Karaffa, L., Fekete, E., Fekete, É., Árnyasi, M., Czeglédi, L., Kövics, G. J., Druzhinina, I. S., and Kubicek, C. P. 2008. Sexual recombination in the Botrytis cinerea populations in Hungarian vineyards. Phytopathology 98:1312-1319.

27. Walker, A-S., Gautier, A., Confais, J., Martinho, D., Viaud, M., Le Pêcheur, P., Dupont, J., and Fournier, E. 2011. Botrytis pseudocinerea, a new cryptic species causing gray mold in French vineyards in sympatry with Botrytis cinerea. Phytopathology 101:1433-1455. 